Acta Hispanica (2018) 23: 163-171

\title{
LOS INMIGRANTES EUROPEOS EN LAS NOVELAS DE RICARDO PIGLIA. LECTURAS PARALELAS DE LAS NOVELAS RESPIRACIÓN ARTIFICIAL Y LA CIUDAD AUSENTE
}

\author{
ÁGNES CSELIK \\ Instituto de Enseñanza Bilingüe Húngaro-Español Károlyi Mihály de Kispest
}

\begin{abstract}
Resumen: En las novelas La ciudad ausente y Respiración artificial de Ricardo Piglia la mayoría de los personajes son inmigrantes europeos que desempeñan un papel clave. Italianos, alemanes, rusos y húngaros, intelectuales, artistas, obreros, y conspiradores que, con su simple presencia, con su historia personal y nacional, con sus tradiciones, su lengua y cultura se encajan en la sociedad argentina, opinan y reflexionan sobre el presente y pasado histórico de su país de origen y a la par conversan y reaccionan sobre el presente y el pasado de su país de residencia dando un enfoque peculiar: argentino y europeo al mismo tiempo.
\end{abstract}

Palabras clave: inmigrantes, enfoque, idioma, transitorio, pérdida

\begin{abstract}
Most of the characters in the novels of Ricardo Piglia, La ciudad ausente and Respiracion artifical are European immigrants who play decisive roles. They are Italians, Germans, Russians, Bulgarians and Hungarians. They are intellectuals, artists, workers and conspirators. Their simple presence fits in the Argentinian society with their personal, national history, traditions, language and culture. They express their opinion and reflect on the historic present and past of their country of origin, while they speak and react to the present of their country of residence. This creates two unmistakable focal points at the same time: one Argentinian and one European.
\end{abstract}

Keywords: immigrants, focus, language, transient, loss

\section{Introducción}

En la conferencia Américas transnacionales: hogar(es), fronteras y transgresiones puede resultar de suma importancia estudiar la presencia y el papel desempeñado de los inmigrantes europeos en las obras de Ricardo Piglia con lecturas paralelas de las novelas Respiración artificial y La ciudad ausente. Ricardo Piglia, fallecido el 6 de enero de 2017, es uno de los autores más importantes de la literatura latinoamericana de la actualidad. Terminó sus estudios universitarios como historiador, lo que en muchos sentidos determina su visión sobre la literatura y sobre la historia argentina y europea reflejada en la literatura. Además de ser historiador 
Los inmigrantes europeos en las novelas de Ricardo Piglia. Lecturas paralelas de las novelas Respiración artificial y La ciudad ausente

y escritor, Ricardo Piglia es crítico y profesor de literatura, y en sus obras literarias, ensayos y entrevistas demuestra un interés muy marcado por la literatura argentina. En 2011 Ricardo Piglia destaca en una entrevista que, en la literatura argentina, desde los principios se percibe la presencia de los inmigrantes:

\begin{abstract}
Muchas veces hemos pensado que el proyecto que inició Sarmiento tenía como objetivo que los inmigrantes ocuparan la tierra, como se hizo en Estados Unidos, tal como cuenta la épica western. Pero cuando llegaron los inmigrantes el campo ya estaba dividido entre los terratenientes y tuvieron que amontonarse en las ciudades, lo que dio una realidad muy diferente. Todo esto daba un contexto que funcionaba muy bien para la novela, ya que siempre nos enfrentamos a dos problemas: dónde se la localiza y en qué tiempo sucede. Es el punto de partida de cualquier narración (García, 2011).
\end{abstract}

Por lo tanto el tema literario ya está dado y el escenario, los inmigrantes ofrecen un punto de partida para las narraciones, tendrán lugar en la urbe, y además, en la vida real son estos mismos inmigrantes los que forman familias de las cuales proceden varios de los grandes autores de la literatura argentina, entre ellos el propio Ricardo Piglia:

Es importante subrayar un aspecto que suele pasarse por alto. Piglia y Saer nacieron entre dos idiomas -aunque circunscritos al ámbito familiar- el italiano y el español en el caso del primero, y el árabe y el español en el segundo. [...] en Saer y Piglia está presente la conciencia de la nueva clase social de hijos de inmigrantes que ellos y otros representan (Diaz, 2007:53).

Acercándose a las novelas tratadas en esta ponencia llama la atención que el espacio propuesto por Ricardo Piglia - la ciudad y los espacios interiores en ellacarece de un carácter acogedor o estable, son lugares de estancia transitoria y en ningún sentido de la palabra pueden ser llamados o entendidos como hogares.

\title{
2. Espacios transitorios versus el Museo
}

En la novela Respiración artificial (1980) el protagonista, Emilio Renzi, busca las huellas de su tío Marcelo Maggi, historiador que a su vez investiga sobre el senador Enrique Ossorio. La investigación se realiza sobre todo a través de 
lecturas y conversaciones apasionadas que giran alrededor de las tradiciones, literatura, ética y moral. Los temas son de interés general y de índole puramente intelectual, puesto que en la realidad argentina la única manera de intentar transmitir información es montar una conspiración perfecta y usar lenguaje cifrado con carácter aparentemente general. El encuentro de los personajes y las conversaciones tienen lugar en bares, en sitios públicos, como si la intimidad, el espacio personal no cupiera en estas existencias.

\begin{abstract}
Vine a este pueblo hace más de treinta años y desde entonces estoy de paso. Estoy siempre de paso, soy lo que se dice un ave de paso, solo que permanezco en el mismo lugar. Permanezco en el mismo lugar, estoy de paso, le digo. Así somos él y yo, tal vez le sirva, le digo a Renzi, tipos sin arraigo, gente anacrónica, los últimos sobreviventes de una estirpe en disolución (Respiración, 112). Este es el lugar donde yo paso mi vida, en esos salones uno puede hacerse la ilusión de que tiene un mundo propio, que está acompañado, que el tiempo no pasa (Respiración, 113).
\end{abstract}

En la novela La ciudad ausente (1992), como el mismo título lo demuestra, es imposible encontrar cualquier tipo de hogar y hay una carencia absoluta de espacios aptos para vivir, o si no vivir dignamente, por lo menos para sobrevivir. En el núcleo de la novela se trenzan por lo menos tres historias: en primer lugar, la de Junior, un periodista, que investiga la aparición de una serie de grabaciones producidas por una máquina, y mientras va descubriendo su propia identidad, en segundo lugar, el origen de la propia máquina, invento ideado por Macedonio Fernández y llevado a cabo por el ingeniero Emil Russo; en tercer lugar, la historia política argentina durante la dictadura militar, justo después de la guerra de las Malvinas. En la ciudad que no tiene nombre siquiera, las calles están vacías, todo está bajo el control absoluto de las patrullas, y la vida se queda relegada a los pasos subterráneos. Macedonio y Junior no tienen hogar, viven en piezas de hotel. En esta ciudad fantasma, el único sitio donde siempre hay un número considerable de personas es en la clínica de psiquiatría, sitio, donde el doctor Arana trata a todo el mundo con electrochoque intentando lograr que los ingresados "canten", delaten, inventen para salvarse de la tortura inhumana encubierta bajo el falso concepto de tratamiento psiquiátrico. La ciudad ausente es un símbolo, reflejo y antítesis de Jerusalén Celestial, que según las esperanzas escatológicas es el descenso a la tierra de la ciudad de Dios $(3,12)$, que lleva el nombre simbólico de "Nueva Jerusalén", escenario de la convivencia, comunidad y unidad perfecta. La ciudad ausente es 
Los inmigrantes europeos en las novelas de Ricardo Piglia. Lecturas paralelas de las novelas Respiración artificial y La ciudad ausente

todo lo contrario, es el vacío total, lugar amenazante y peligrosa que no es hogar y tampoco ofrece protección alguna.

Frente a paraderos transitorios donde los personajes pasan su tiempo, en ambas novelas de Ricardo Piglia aparece el concepto del museo, como algo fijo que sirve para salvar los valores amenazados por el sistema. La idea del Museo procede de Macedonio Fernández que en su obra Museo de la Novela de la Eterna elabora el concepto de la novela-museo. Ricardo Piglia edita un manual con el título Diccionario de la Novela de Macedonio Fernández, en el que el Museo está definido:

\footnotetext{
Sitio de la Inolvidable donde se vencerá el Olvido-Muerte. [...] Lugar donde se presta vida, donde es posible la Eterna, con su toda presencia en el Presente y su olvido total del Pasado. [...] Lugar de entrada para perderse y en donde el Autor salvará la vida del Lector (Diccionario, 64-65).
}

En La cindad ausente la máquina que produce los relatos está expuesta, presa, vigilada y controlada en el Museo. La llegada al Museo es un ritual: hay que dejar atrás la ciudad, subir una rampa, con lo cual se está cambiando nivel espacial y simbólico, cruzar una frontera y en medio de una sala circular se encuentra la fuerza vital, la máquina narradora, Elena la Eterna.

El Museo quedaba en una zona apartada de la ciudad, cerca del parque y atrás del Congreso. Había que subir una rampa y cruzar un corredor con paredes de acrílico para desembocar en el salón circular donde se exhibía la máquina (La ciudad, 61).

En el Museo los relatos entran en diálogo entre sí e incluyen en este fluir de comunicación al visitante y al lector, la dicotonomía tradicional de realidadficción queda diluida en el corpus de la novela, los personajes de un relato salen de su historia y entran en otra, Junior es visitante, lector, participante y personaje a la vez.

En Respiración artificial el conde Tokray expone la idea de convertirse él mismo en un museo vivente de las costumbres y modales de la antigua Rusia, de este modo, en su persona persistirá la memoria de un tiempo feliz, cuya existencia en sí servirá para hacer reflexionar a los visitantes e iniciará un movimiento de conciencia y provocará la derrota del Régimen y la Restauración (Respiración, 120). El deseo de ser un Museo es un acto de resistencia y valentía. 
En el mundo de las novelas analizadas los hogares no existen, los bares y los hoteles son paraderos temporales convertidos en permanentes, el Museo es donde (La ciudad ausente) o quien (Respiración artificial) salva el Presente con su existencia, con su narración. El Museo es el Presente Eterno, el tiempo del que los personajes se aluden hablar, porque en los horrores de la guerra sucia hablar de lo indecible pone en peligro la supervivencia del lenguaje. El Museo es la salvación posible tanto para el autor, como para los personajes y para el lector.

\section{Personajes europeos, lengua madre}

En Respiración artificial en medio de la guerra sucia argentina aparecen, cuentan, sueñan personajes de origen diverso, mayormente europeo, los que conversan sobre tradiciones literarias, filosóficas, consecuencias históricas y morales, y sobre el pasado tanto europeo como argentino. Entre otros hablan sobre Wittgenstein, Descartes, Hegel, Hitler, Franz Kafka, Witold Gombrowitz, Faulkner, Alberdi, Sarmiento, Borges, Leopoldo Lugones, etc. para encubrir y descifrar a la vez los horrores del presente.

La compañía de los amigos se compone de Tardewski, filósofo polaco de talento brillante que huyó a Argentina del fascismo europeo; de Antón Tokray, hijo natural de un noble ruso, conde de título nobiliario que sufrió todas las desventajas que la revolución produjo en su familia; de Rudolf Van Maier que ha sido, casi con seguridad, un nazi. Por supuesto, como todos los nazis, entró en el partido obligado. El Profesor Maggi, italiano de origen que está ausente y en esta serie de conversaciones es reemplazado y buscado por Emilio Renzi, primo del Profesor. Emilio Renzi es personaje conformado por el segundo nombre de pila y el apellido de la madre de Ricardo Piglia y "alter ego" suyo desde hace décadas, por ende Emilio Renzi es de procedencia italiana igual que Marcelo Maggi y Ricardo Piglia. El polaco, el ruso, el alemán y el italiano forman una tertulia de inmigrantes europeos en la Argentina. Tardewski analiza de esta manera la reunión de los amigos: "Nos hemos reunido, quizás, porque los tres somos expatriados. Extranjeros. Escorias que la marea de las guerras europeas depositó sobre estas playas" (Respiración, 113).

La marea de las guerras europeas depositó a otros personajes en La ciudad ausente. Emilio Renzi le cuenta a Junior en la redacción de El Mundo: 
Los inmigrantes europeos en las novelas de Ricardo Piglia. Lecturas paralelas de las novelas

Respiración artificial y La cindad ausente

Cuando era estudiante que vivía en La Plata, me ganaba la vida enseñando español a los derechistas checos, polacos y croatas a los que el avance de la historia estaba expulsando de sus territorios. En general vivían en un viejo barrio de Berisso llamado El Imperio Austro-Húngaro, donde desde los finales del siglo XIX se habían asentado los inmigrantes del centro de Europa (La ciudad, 15).

Emilio Renzi, descendiente italiano habla en La ciudad ausente de los inmigrantes con Junior, periodista compañero, su nombre completo es Miguel Mac Kensey, de una familia de origen inglés, que para más inri es solo uno de la serie de personajes cuyo nombre empieza con Mac en la novela; además de él aparecen en la novela Mac, el que trabaja en el taller clandestino en Los nudos blancos, y McKinley, jefe de estación del Ferrocarril Central argentino. Todos serán descendientes anglosajones. Las investigaciones de Junior le llevan al ingeniero Emil Russo, realizador de la máquina ideada por Macedonio Fernández y el nombre del ingeniero es clara alusión a Emile Rousseau, autor francés y a la vez en su apellido se descubre el adjetivo ruso, mientras la novela aclara que en realidad no se trata de ruso, sino de un húngaro: “[...] no era ruso sino húngaro, que era ingeniero y había estudiado con Moholy-Nagy que se vino escapando de los nazis" (109) y que "Russo tenía muchas dificultades con el idioma y su ilusión era volver a Europa. Macedonio era el único que lo entendía y hablaba con él” (116).

Para los inmigrantes, sobre todo para los intelectuales, uno de los problemas más difíciles a que tienen que enfrentarse es la pérdida del idioma materno que dominan con perfección total, la imposibilidad casi absoluta de poder expresarse en el mismo nivel que en la lengua madre o intentar adquirir en el nuevo destino un prestigio intelectual semejante al que poseían en el país de origen. Es el caso de Emil Russo en Respiración artificial y de Lazlo Malamüd en La ciudad ausente que había sido un crítico famoso y profesor de literatura en la ciudad de Budapest y era el mayor experto centroeuropeo en la obra de José Hernández. Su traducción del Martín Fierro al húngaro había recibido el premio anual de la Asociación Internacional de Traductores (París, 1949).

Era marxista e integró el círculo Petőfi y sobrevivió a los nazis, pero se escapó en 1956 cuando entraron los tanques rusos en Hungría, porque no pudo soportar que lo masacran aquellos en quienes había depositado su esperanza. Aquí lo rodearon los derechistas y para salir ese círculo buscó el contacto con los grupos intelectuales, a los que se dio a conocer como traductor de Hernández. Leía correctamente el español, pero no podía hablarlo. 
Ágnes Cselik

Se sabía el Martín Fierro de memoria y ése era su vocabulario básico. Había venido acá con la ilusión de conseguir un cargo en la universidad y para obtenerlo sólo tenía que ser capaz de enseñar en español. [...] Hablaba conmigo en un idioma imaginario, lleno de erres guturales y de interjecciones gauchescas. A media lengua trataba de explicarme la desesperación de verse condenado a expresarse como un chico de tres años (La ciudad, 15-16).

La tragedia consiste en "contar con palabras perdidas la historia de todos, narrar en una lengua extranjera". (La ciudad, 17) Lazlo Malamüd, igual que Emil Russo son fracasados. Por no dominar el español pierden prestigio, trabajo, autoestima y no llegan a conseguir relaciones interpersonales. Russo, siendo ingeniero, es capaz de trabajar sin palabras en la máquina narradora, paradójicamente será ésta la que expresa verbalmente lo que no fue posible para su creador. Lazlo Malamüd, en cambio siendo traductor e hispanista no tiene otro medio para expresarse que el idioma y justo es esta herramienta la que le falla en el exilio.

La pérdida lingüística e intelectual se vincula con la pérdida de la identidad a la vez. El conde ruso, Antón Tokray confiesa en Respiración artificial sobre ello:

¿Y sabe por qué, a pesar de todo, estoy tratando a ir? Porque hace más de cincuenta años que no me encuentro en un lugar donde más de dos personas vivas hablen en ruso. Escucho el idioma de mis antepasados en los sueños [...] (Respiración, 118).

Tardewski, el polaco declara de su parte: "No soy bueno para los juegos de palabras, dijo Tardewski entre paréntesis, lo era antes, quiero decir, cuando podía jugar con la lengua de mi madre." (Respiración, 167) y le cuenta a Renzi la absoluta imposibilidad de decir la verdad cuando se ha abandonado la lengua materna. "Una de las primeras cosas que se pierde al cambiar de idioma es la capacidad de escribir." (Respiración, 105)

La tragedia de Tardewski es que al llegar a Argentina y sin saber español escribe un artículo sobre su gran descubrimiento, sobre la posible relación entre el nazismo y la obra de su autor favorito que también vivió y sufrió entre dos idiomas siendo de habla alemana en Praga, Franz Kafka. Tardewski redacta su artículo en inglés, y lo hace traducir por una chica que no sabe ni polaco ni inglés, pero hace una excelente traducción al español. La primera paradoja de la situación es que Tardewski tiene que confiar a ciegas en una traductora desconocida de la que lo único que sabe con toda seguridad es que no domina las mismas lenguas que él 
Los inmigrantes europeos en las novelas de Ricardo Piglia. Lecturas paralelas de las novelas Respiración artificial y La ciudad ausente

mismo, el autor del texto original. La segunda es que el propio autor, Tardewski, no puede leer el texto publicado por él, y la tercera es que el artículo aparece con una errata en el nombre del autor: en vez de Tardewski figura Vladimir Tardowski en la prensa y encima aquella misma mañana entran ladrones en su casa y le roban todo, hasta los apuntes de su investigación. La desposesión lingüística, cultural, intelectual y física de Tardewski es una metáfora perfecta de su situación.

El arraigo lingüístico determina casi todo: pasado, presente, futuro, identidad e integridad, sin embargo en La isla de La ciudad ausente hay un cambio continuo de lenguas, y la vigencia de los universos creados por la lengua se pierde a la hora del cambio de idioma.

El lenguaje se transforma según ciclos discontinuos que reproducen la mayoría de los idiomas conocidos. Los habitantes hablan y comprenden instantáneamente la nueva lengua, pero olvidan la anterior (Respiración, 120).

Todo permanece vigente mientras sigue en función la misma lengua. Con cada cambio de idioma grandes poetas dejan de serlo y surgen otros clásicos nuevos, llegan cartas escritas en signos ya desconocidos, hombre y mujer se aman en un idioma y son desconocidos o tal vez hostiles en otro. El cambio de idioma es impredecible, los ritmos del cambio son variables, a veces un idioma dura dos años, otras veces suceden quince modificaciones en doce días.

En esa isla, la multiplicidad de las formas de vida se da en la superposición de las lenguas. [...] La ficción de la isla anula la brecha entre lo posible y lo imposible, porque todas las posibilidades coexisten por la simple efectuación de la lengua. Utopía de la anulación de lo real, la política de la ficción frente al lenguaje del Estado. Las coordinadas del tiempo, y el espacio se anulan mutuamente por la superposición de las lenguas (Bueno, 249).

La isla es hogar de la máquina narradora, el Presente Eterno de una lengua y en esa función de guardar el Presente La isla se entrelaza con El Museo; puede estar dentro y fuera de él o al revés, El Museo puede ser creación de la máquina en La isla que es el mundo de una realidad efímera, de la memoria perdida y recuperada, el sitio, donde los borradores en la vida son posibles, donde el personaje, autor y lector se fusionan, se completan y sobre todo, se salvan. 
Ágnes Cselik

\title{
4. Conclusión
}

Con la ayuda de historias entretejidas, con la amalgama de categorías tradicionales de realidad-ficción, tiempo y espacio, a través de los discursos de inmigrantes europeos, de clásicos literarios y grabaciones de la máquina que cuenta versiones infinitas de la misma historia, Ricardo Piglia llega a entrar en la pesadilla del presente y escribir sobre ella, porque

\begin{abstract}
los escritores verdaderamente grandes son aquellos que enfrentan siempre la imposibilidad absoluta de escribir. [...] ¿Cómo hablar de lo indecible? [...] Ese mundo está más allá del lenguaje, es la frontera donde están las alambradas del lenguaje. Alambre de púas: el equilibrista camina, descalzo, solo allá arriba y trata de ver si es posible decir algo sobre lo que está del otro lado (Respiración, 209).
\end{abstract}

Ricardo Piglia es un equilibrista descalzo en el alambre de púas, es un escritor verdaderamente grande que sin lugar a dudas ha llegado a decir algo sobre lo indecible.

\section{Bibliografía}

Bueno, Mónica. 2017. "La forma de una vida literaria" Revista Landa, 249. Fecha de consulta: 19 de agosto de 2017. Asequible en: https://repositorio.ufsc.br / bitstream/handle/123456789/177417/16\%20DOSSIER $\% 209 \% 20$ Monica $\% 2$ 0Bueno $\% 20-\% 20 \mathrm{La} \% 20$ forma $\% 20 \mathrm{de} \% 20$ una $\% 20$ vida $\% 20$ literaria $\% 20$ Ricardo $\% 20$ Piglia.pdf?sequence $=1$

Diaz Quiñones, Arcadio. 2007. "La literatura de una nación pequeña” Rose Corral (ed.). Entre ficción y reflexión. Juan José Saer y Ricardo Piglia. México D.F.: El Colegio de Mexico AC. Fecha de consulta: 19 de agosto de 2017. Asequible en: https://seminarioeuraca.files.wordpress.com/2012/10/diaz-quic3b1ones-laliteratura-de-una-nacion-pequec3b1a-saer-y-piglia-2007.pdf

García, Gastón. 2011. "Entrevista a Ricardo Piglia” Letras Libres, 31 de enero de 2011. Fecha de consulta: 10 de septiembre de 2017. Asequible en:

http://www.letraslibres.com/mexico-espana/entrevista-ricardo-piglia-0

Piglia, Ricardo (ed.). 2000. Diccionario de la Novela de Macedonio Fernández. Tezontle. Buenos Aires: Fondo de Cultura Argentina S.A.

Piglia, Ricardo. 1992. La ciudad ausente. Buenos Aires: Espasa Calpe Argentina.

Piglia, Ricardo. 1996. Respiración artificial. Buenos Aires: Espasa Calpe Argentina. 